\title{
Prevalence of plexiform neurofibroma in children and adolescents with type I neurofibromatosis
}

\author{
Luiz G. Darrigo Jr., ${ }^{1}$ Mauro Geller, ${ }^{2}$ Aguinaldo Bonalumi Filho, ${ }^{3}$ David R. Azulay ${ }^{4}$
}

\begin{abstract}
Objective: To assess prevalence of plexiform neurofibroma in children and adolescents with type I neurofibromatosis and its malignant potential.
\end{abstract}

Methods: A retrospective study was conducted through analysis of the database at Centro Nacional de Neurofibromatose [Brazilian Neurofibromatosis Center], collected from the following reference services between 1996 and 2004: Instituto de Dermatologia Prof. Rubem David Azulay da Santa Casa de Misericórdia do Rio de Janeiro, Instituto de Pediatria e Puericultura Martagão Gesteira da Universidade Federal do Rio de Janeiro and Department of Immunology and Microbiology at Faculdade de Medicina de Teresópolis.

Results: Over that period, 104 patients aged between 1-17 years were admitted with clinical diagnosis of type I neurofibromatosis. Of these, 53 were male and 51 were female, and 28 patients ( 15 male and 13 female) had plexiform neurofibroma (26.9\%). Division by age group resulted in $21.42 \%$ (six) between $1-5$ years; $35.71 \%$ (10) between 6-12 years and $42.85 \%$ (12) between $13-17$ years. Of the 104 patients, two developed a malignant peripheral nerve sheath tumor (1.92\%).

Conclusions: Plexiform neurofibromas are relatively common manifestations in patients with type I neurofibromatosis and may be a cause of significant increase in morbidity and mortality among patients. In this study, we conclude that frequency of plexiform neurofibroma and its malignant potential in the population studied is in agreement with data from the international literature.

J Pediatr (Rio J). 2007;83(6):571-573: Type I neurofibromatosis, plexiform neurofibroma, prevalence.

\section{Introduction}

Type I neurofibromatosis (NF1) is a genetic, multisystemic disorder that has major cutaneous manifestations, such as cafe-au-lait spots, ephelides and neurofibromas. ${ }^{1,2} \mathrm{NF} 1$ is considered the most common "new" spontaneous, dominant, genetic mutation in human beings, with complete penetrance, despite having variable expression. ${ }^{1,3,4}$ Incidence of
NF1 is approximately $1: 2.500$ newborns, affecting all races and having identical correlation between men and women. ${ }^{1}$ It is estimated that there are today around 80,000 cases of NF1 in Brazil, and around 1.5 million cases worldwide. ${ }^{5}$

NF1 was described in 1882 by Friedrich Daniel von Recklinghausen, who suggested the name neurofibroma for neural tissue tumors present in this disease and

1. Residente em Pediatria, Hospital do Servidor Público Municipal de São Paulo, São Paulo, SP, Brazil. Especializando em Pediatria Clínica, Universidade de São Paulo (USP), São Paulo, SP, Brazil.

2. Professor titular, Faculdade de Medicina, Fundação Educacional Serra dos Órgãos (FESO), Teresópolis, RJ, Brazil. Membro, Conselho Diretor, International Neurofibromatosis Association.

3. Professor, Pós-Graduação em Dermatologia, Hospital Naval Marcílio Dias, Rio de Janeiro, RJ, Brazil.

4. Chefe de Serviço, Instituto de Dermatologia Professor Rubem David Azulay, Santa Casa de Misericórdia do Rio de Janeiro, Rio de Janeiro, RJ, Brazil. Professor, Fundação Técnico-Educacional Souza Marques, Pontifícia Universidade Católica (PUC) e Universidade Federal do Rio de Janeiro (UFRJ), Rio de Janeiro, RJ, Brazil.

This study was carried out at Centro Nacional de Neurofibromatose (CNNF), Rio de Janeiro, RJ, Brazil. Reference services: Instituto de Dermatologia Professor Rubem David Azulay, Santa Casa de Misericórdia do Rio de Janeiro; Instituto de Pediatria e Puericultura Martagão Gesteira; Universidade Federal do Rio de Janeiro (UFRJ); Departamento de Imunologia e Microbiologia, Faculdade de Medicina de Teresópolis.

No conflicts of interest declared concerning the publication of this article.

Suggested citation: Darrigo Jr. LG, Geller M, Bonalumi Filho A, Azulay DR. Prevalence of plexiform neurofibroma in children and adolescents with type I neurofibromatosis. J Pediatr (Rio J). 2007;83(6):571-573.

Manuscript received Mar 07 2007, accepted for publication May 302007.

doi 10.2223/JPED.1718 
neurofibromatosis for the condition with multiple neurofibromas. ${ }^{6}$

Diagnosis of NF1, whose criteria were established by the National Institutes of Health (NIH) in 1987 and updated in 1997 (Table 1), depend on a careful clinical examination of patients, on their parents and siblings and on a detailed family history, including clinical information and sometimes complementary examinations. ${ }^{7,8}$

NIH criteria may be insufficient for NF1 diagnosis in children who represent the only case in the family and only show cafe-au-lait spots, without other manifestations. In this case, annual follow-up of suspected case is recommended, and fluorescent in situ hybridization (FISH) or the technique of direct analysis of DNA mutation can be used to clarify possible diagnostic doubts or simply to help establish an earlier diagnosis. ${ }^{9}$ On the contrary, those who inherit the disease from one of the parents can usually be identified during the first year of life, because diagnosis only requires one additional characteristic, besides positive family history. ${ }^{7}$

Plexiform neurofibroma (PN), also called plexiform neuroma, pachydermatocele or neurofibromatous elephantiasis, is classified as a benign peripheral nerve sheath tumor that surrounds multiple nervous fascicles. ${ }^{5,10}$ It is a nonmetastatic, highly vascularized, locally invasive tumor that has slow growth. ${ }^{5} \mathrm{PN}$ are one of the significant complications of NF1, which may occur during childhood and rarely develop after adolescence. PN can originate malignant peripheral nerve sheath tumor (MPNST), which occurs in 2-5\% of patients with plexiform neurofibroma. ${ }^{5}$ MPNST, previously described as neurofibrossarcomas or malignant schwannomas, are the main cause of death and the most common neoplasia in this group. ${ }^{5}$

This study aims at assessing prevalence of PN in children and adolescents with NF1, as well as the malignant potential of these neurofibromas.

Table 1 - Diagnostic criteria of type I neurofibromatosis (NIH, 1990)*

Six or more cafe-au-lait spots $>5 \mathrm{~mm}$ in prepubertal patients or $>15 \mathrm{~mm}$ in postpubertal patients

Two or more neurofibromas of any type or a plexiform neurofibroma

Ephelides in axillary and inguinal regions

Optic glioma

Two or more Lisch nodules

A characteristic bone lesion, such as sphenoid bone dysplasia or thinning of cortex long bones, with or without pseudoarthroses.

Incomplete status, but having a first-degree relative (parent, brother or son) who meets NIH criteria

$\mathrm{NIH}=$ National Institutes of Health.

* Two or more criteria are needed for diagnostic confirmation.

\section{Methods}

Constant observations of the database at Centro Nacional de Neurofibromatose (CNNF) [Brazilian Neurofibromatosis Center], collected from the following reference services between 1996 and 2004: Instituto de Dermatologia Professor Rubem David Azulay da Santa Casa de Misericórdia do Rio de Janeiro, Instituto de Pediatria e Puericultura Martagão Gesteira da Universidade Federal do Rio de Janeiro and Department of Immunology and Microbiology at Faculdade de Medicina de Teresópolis. Over that period, 104 patients aged between 1-17 years were admitted. Patients admitted to CNNF come from different Brazilian states, and some are from neighboring countries, such as Uruguay, Peru, Bolivia and Mexico. All patients were given care by at least one of the authors, and clinical diagnosis of NF1 was performed according to the criteria proposed by NIH Consensus Conference.

The project was approved by the Research Ethics Committee at UNIFESO.

\section{Results}

Of the 104 patients aged less than 17 years, 53 were male and 51 were female, which shows gender equity. Of these, 28 patients (26.9\%) - 15 male and 13 female - had PN, and the data were in agreement with some studies reporting a $15 \%$ prevalence; however, others indicate prevalence between $16-40 \%$ in patients with NF1. ${ }^{11}$ In another study, Huson et al. found prevalence of PN evident on physical examination in $32 \%$ of patients with NF1. ${ }^{11}$

Division by age group resulted in $21.42 \%$ (six) between $1-5$ years; $35.71 \%$ (10) between $6-12$ years and $42.85 \%$ (12) between $13-17$ years. In our study, two patients (1.92\%) progressed with MPNST.

\section{Discussion}

Although frequent in patients with NF1, PN are not a pathognomonic finding of this syndrome. ${ }^{12} \mathrm{PN}$ are a major cause of clinical complications in NF1 and develop especially in childhood and adolescence. Their most common location is trunk (43\%), followed by head and neck (42\%) and limbs (15\%). ${ }^{13} \mathrm{PN}$ have a much variable natural history, since some lesions can remain quiescent for a long time, whereas others can grow aggressively, especially during childhood and adolescence. PN require clinical follow-up, ${ }^{5,10}$ which should be performed annually through clinical and imaging examinations, such as X-ray, computed tomography (CT) and magnetic resonance (MR), this latter being considered as the gold standard. MR should be used not only to locate PN, but also to measure it, providing useful data for patient follow-up. ${ }^{5}$

During follow-up, one should be alert to occurrence of growth or pain in plexiform neurofibromas, which suggests malignant transformation. In these cases, tumor biopsy is indicated. ${ }^{1,5,9}$ Another laboratory tool available for detection 
of MPNST is positron-emission tomography (PET) with glucose analog F-fluorodeoxyglucose (FDG). It is a technique that allows visualization and quantification of glucose metabolism in cells and reflects increased metabolism of malignant tumors. ${ }^{5}$ Risk of MPNST development has been estimated between $2-5 \%,{ }^{1,5}$ which are extremely aggressive in these cases with reserved prognosis (5-year survival in 34-52\%). ${ }^{1,5}$ Other less frequent neoplastic processes include optic glioma, astrocytoma, pheochromocytoma, rhabdomyosarcoma and juvenile chronic myeloid leukemia. ${ }^{5}$ In these cases, treatment should be the same as that performed in children with neoplasia and without NF1. ${ }^{14}$

PN can be surgically treated, despite results being often unsatisfactory, since they are closely involved with nerves and due to their tendency of recurrence. ${ }^{1}$ Prognostic factors for recurrence are being less than 10 years in initial surgery, presence of initial tumor after surgery and tumor site (head and neck). ${ }^{5}$

Friedrich et al. suggest that early surgical interventions in small-sized PN in children can be advantageous, especially in the strategy to prevent their progression. ${ }^{15}$ Therefore, early diagnosis of a possible malignant transformation followed by surgical resection can positively change prognosis.

PN can be symptomatic at birth or become symptomatic through time. Early occurrence supports the idea that PN are congenital lesions, although there may be patients that develop plexiform neurofibromas after 20 years of age. ${ }^{5}$

$\mathrm{PN}$ are relatively common manifestations in patients with NF1 and may be a cause of significant increase in morbidity and mortality among patients. ${ }^{5}$

We conclude that frequency of PN in our population is in agreement with data from the international literature. ${ }^{13}$

\section{References}

1. Geller M, Bonalumi AF. Neurofibromatose. In: Carakushansky G. Doenças Genéticas em Pediatria. Rio de Janeiro: Guanabara Koogan; 2001. p. 377-90.

2. DeBella K, Szudek J, Friedman M. Use of the national institutes of health criteria for diagnosis of neurofibromatosis 1 in children. Pediatrics. 2000;105:608-14.
3. Carey JC, Viskochil H. Neurofibromatosis type 1: A model condition for the study of molecular basis of variable expressivity in human disorder. Am J Med Genet. 1999,89:7-13.

4. Friedman JM. Epidemiology of neurofibromatosis type 1. Am J Med Genet. 1999;89:1-6.

5. Geller M, Bonalumi AF. Neurofibromatose; clínica, genética e terapêutica. Rio de Janeiro: Guanabara Koogan; 2004.

6. Viskochil D. Neurofibromatosis 1. Introduction. Am J Med Genet. 1999;89:v-viii.

7. Trovo AB, Goloni-Bertollo EM, Tajara EH. Neurofibromatose tipo 1: uma revisão. HB Cientifica. 2002;9:98-110.

8. Neurofibromatosis. NIH Consens Statement 1987 Jul 13-15;6:119.

9. Eichenfield LF, Levy ML, Paller AS, Riccardi VM. Guidelines of care for neurofibromatosis type 1. American Academy of Dermatology Guidelines/Outcomes Committee. J Am Acad Dermatol. 1997; 37:625-30.

10. Geller M, Bonalumi AF, França FC, Nunes FP. Neurofibromatose. Síndrome de Von Recklinghausen: histórico, diagnósticos, exames clínicos e laboratoriais. JBM. 1998;75:15-21.

11. Huson SM, Harper PS, Compston DA. Von Recklinghausen neurofibromatosis. A clinical and population study in south-east Wales. Brain. 1988; 111:1355-81.

12. Lin V, Daniel S, Forte V. Is a plexiform neurofibroma pathognomonic of neurofibromatosis type I? Laryngoscope. 2004;114:1410-4.

13. Waggoner DJ, Towbin J, Gottesman G, Gutmann DH. Clinicbased study of plexiform neurofibromas in neurofibromatosis 1 . Am J Med Genet. 2000;15;92:132-5.

14. Health Supervision for Children with Neurofibromatosis. American Academy of Pediatrics. Committee on Genetics. Pediatrics. 1995; 96:368-72.

15. Friedrich RE, Schmelzle R, Hartman M, Fünsterer C, Mautner VF. Resection of small plexiform neurofibromas in neurofibromatosis type 1 children. World J Surg Oncol. 2005;3:6.

Correspondence:

Luiz Guilherme Darrigo Junior

Rua Martiniano de Carvalho, 1049, Paraíso

CEP 01321-001 - São Paulo, SP - Brazil

Tel.: +55 (12) 9151.6435

E-mail: guimedicina@gmail.com 